\title{
Determining the ratio of the number of recoil electrons to the number of photoelectrons using a new method
}

\author{
Determinación de la relación entre el número de electrones de retroceso y el \\ número de fotoelectrones mediante un nuevo método
}

\author{
Petr M. Kosianov \\ Industrial University of Tyumen,Nizhnevartovsk, Russian Federation. \\ *kaf_gendnv@mail.ru, kospiter2012@yandex.ru
}

(recibido/received: 21-mayo-2021; aceptado/accepted: 17-julio-2021)

\begin{abstract}
The problem in question is relevant due to discrepancy between the results of theoretical and known experimental studies of various interactions of ionizing emission photons with substances, in particular, photo effect and Compton scattering of these photons. The study aimed at carrying out specific measurements using a new method of simultaneously determining the ratio of the number of recoil electrons to the number of photoelectrons. Analysis of the results showed that there are significant discrepancies between theoretical calculations and experimental data. New values of simultaneously measured ratios of cross-sections for heavy atoms using a method invented by the author, and old measurements of these ratios for light atoms usingWilson cloud chamber, when compared with theoretical calculations, show that a significant (by one order and more) one-direction discrepancy is seen for X-ray and gamma emissions over a range of energies in question.It is shown that these discrepancies might be attributed to the fact that an atomic electron is in a free state for a while. Compton scattering occurs with a free electron; photo effect involves only bound electrons. Therefore, Compton scattering cross section is proportional to a period of time, during which electron was in a free state, whereas photo effect cross section is proportional to a time period, during which electron was in a bound state. The article materials might be helpful to perform both fundamental, and applied studies on interaction of light quanta with substance including modelling the phenomena under examination.
\end{abstract}

Keywords: Simultaneous measurements; Photo effect; Compton scattering; Bound state of electron; Free state of electron.

\section{RESUMEN}

La urgencia del problema investigado se debe a la divergencia de los resultados de las investigaciones teóricas y experimentales conocidas de los diferentes tipos de interacción de los fotones de la radiación ionizante con las sustancias, en particular, el fotoefecto y la dispersión Compton de estos fotones. El objetivo del trabajo era realizar mediciones específicas mediante un nuevo método, determinando simultáneamente la relación entre el número de electrones de retroceso y el número de fotoelectrones. El análisis de los resultados mostró que existe una marcada diferencia entre los cálculos teóricos y los datos experimentales. Los nuevos resultados de las relaciones de sección transversal medidos simultáneamente para los átomos pesados mediante el método desarrollado por el autor y las antiguas mediciones de estas 
relaciones para los átomos ligeros mediante la cámara de Wilson, al compararlos con los cálculos teóricos, muestran que existe una diferencia unidireccional considerable (de un orden de magnitud o más) para los rayos X y los gammas del rango de energía considerado. Se demuestra que estas discrepancias pueden explicarse porque el electrón del átomo está en estado libre durante un tiempo determinado. La dispersión Compton se produce en un electrón libre, el fotoefecto sólo en un electrón ligado. Por lo tanto, la sección transversal de la dispersión incoherente es proporcional al tiempo del electrón en el estado libre, mientras que la sección transversal del efecto fotoeléctrico es proporcional al tiempo del electrón en el estado ligado. Los materiales de este artículo pueden ser útiles para la investigación tanto fundamental como aplicada de la interacción de los cuantos de luz con la materia, incluyendo la simulación de los fenómenos en cuestión.

Palabras clave: Mediciones simultáneas; Fotoefecto; Dispersión Compton; Estado de electrones ligados; Estado de electrones libres.

\section{INTRODUCTION}

Measuring electron streams in substances is relevant both for evaluating validity of light quanta-substance interaction theory and solving different applied problems (on determining electrical conductivity, for instance), including modelling of phenomena and processes under review. However, since methods of energy-dispersion registration of recoil electrons and photoelectrons, for example using Wilson cloud chamber, or electronic spectroscopy (Briggs, 1987; Lukyanova \& Podolyako, 2004; Shpolskiy, 1950, 1974; Thompson et al., 1985), in condensed media are challenging, it is a matter of priority to develop new experimental methods.

This study examines potential use of primary emission characteristic and incoherently scattered streams as a source of information about the above phenomena.It is shown that the ratio of mass coefficient of the primary emission incoherent scattering section to the mass coefficient of primary emission photoelectric absorption can be defined from simultaneously measured ratios of intensities of characteristic and incoherently scattered emissions in substance.

\section{METHODS AND RESULTS}

\subsection{Results obtained by the known method}

The first experiments on detecting recoil electrons when scattering gamma and X-rays in air were conducted by making use of Wilson cloud chamber (Shpolskiy, 1974). The results of measurements are listed in Table 1 .

Table 1. Experimental data of ratios of intensities of recoil electrons and photoelectrons and their sections, respectively

\begin{tabular}{|l|c|c|c|c|}
\hline № & Wavelength $(\AA)$ & Energy $(\mathrm{keV})$ & $\mathrm{N}_{\mathrm{c}} / \mathrm{N}_{\mathrm{pe}}$ & $\sigma / \tau$ \\
\hline 1 & 0,71 & 17,49 & 0,10 & 0,27 \\
\hline 2 & 0,44 & 28,23 & 0,90 & 1,20 \\
\hline 3 & 0,29 & 42,83 & 2,70 & 3,80 \\
\hline 4 & 0,20 & 62,21 & 9,0 & 10,0 \\
\hline 5 & 0,17 & 73,06 & 17,0 & 17,0 \\
\hline 6 & 0,13 & 95,55 & 72,0 & 32,0 \\
\hline
\end{tabular}

where $\mathrm{Nc} / \mathrm{Npe}$ is a ratio of the number of recoil electrons to the number of photoelectrons, $\sigma / \tau$ is a ratio of the primary emission incoherent scattering section coefficient to the primary emission photoelectric absorption coefficient . Here it is assumed that $\mathrm{Nc} / \mathrm{Npe}=\sigma / \tau$. It is obvious that usingboth this method and electronic spectroscopy methods in solid substances, especially, in metals, is problematic. Indeed, it is almost impossible to single out and distinguish photoelectrons and recoil electrons against the background of "electron gas" deep in conductor. 
Figure 1 shows for comparison: experimental curve and theoretical curve calculated on the basis of model (Lukyanova \& Podolyako, 2004) taking into account scattering effect exerted on bound electrons of atoms.

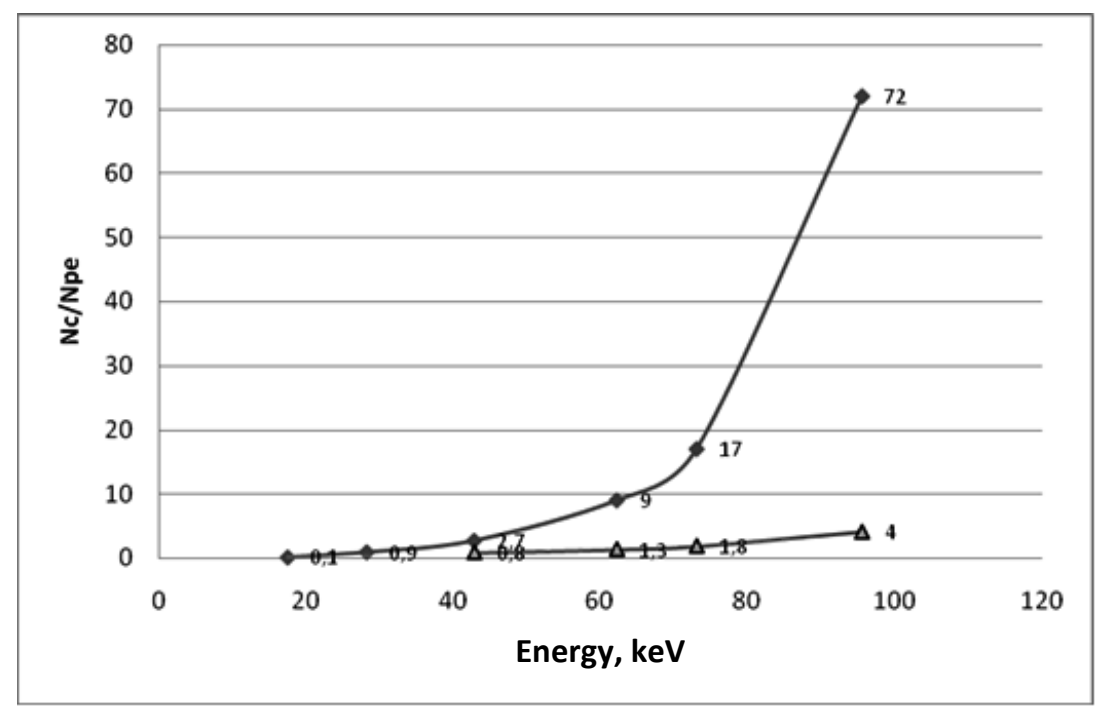

Figure 1. Experimental - $\diamond$ and theoretical $-\Delta$ dependence of ratio of the number of recoil electrons to the number of photoelectrons on primary emission energy

As is evident, a discrepancy between the curves is of one order and more. It is clear that the experimental data are insufficient to ensure agreement of theory with experience.

\subsection{New method}

Many papers were devoted to studying and using spectral ratio method (Kosianov, 2005, 2012; Mamikonyan, 1976; Revenko, 2000). A large database of experimentally measured ratios of intensities of the characteristic and incoherently scattered X-ray and gamma emissions in various substances was built up. The author obtained the following expression (Kosianov, 2016; Morrison, 1967):

$$
y=\frac{J_{1}}{J_{2}}=2 \eta \frac{S_{K}-1}{S_{K}} \frac{p_{k} \tau_{m}}{\sigma_{H} \alpha} \frac{1}{\left[\frac{\left(E_{0} / E_{i}\right)^{3}}{S_{k}}+1\right]}
$$

where: $\eta$-fluorescence yield coefficient $* ; \sigma_{n}$ - mass coefficient of the primary radiation incoherent scattering cross section in sample; $\alpha$ - anisotropy coefficient of incoherently scattered radiation angular distribution $; p_{k}$ - transition probability of an atom, excited to $K$-level with emission of the characteristic i-line radiation $* ; S_{K}$-value of $K$ (or $L$ ) -absorption jump of the analyzed element $* ; \tau_{M}$ - mass coefficient of the primary radiation photoelectric absorption of the element $\left[\mathrm{m}^{2} / \mathrm{kg}\right]$;

*Dimensionless values

And, the resulting expression (1) enables to obtain the desired ratio of the mass coefficient of the primary radiation incoherent scattering cross section to the mass coefficient of the primary radiation photoelectric absorption:

$$
\frac{\sigma_{H}}{\tau_{m}}=\frac{N_{c}}{N_{P e}}=\frac{J_{2}}{J_{1}} 2 \eta \frac{S_{K}-1}{S_{K}} \frac{p_{k}}{\alpha} \frac{C}{\left[\frac{\left(E_{0} / E_{i}\right)^{3}}{S_{k}}+1\right]},
$$


where anisotropy coefficient of incoherently scattered radiation angular distribution - is $\alpha$, for angles $\psi=\varphi=45^{\circ}$ and,thus, for scattering angle $\theta=90^{\circ}$, and energies from $10 \mathrm{keV}$ to $100 \mathrm{keV}$, varies from 0.4 to 0.2 ; transition probability of an atom, excited to $K$ - level with $i$-line characteristic radiation emission $-p_{K} \geq 0,9$ (Morrison, 1967), fluorescence yield $\eta$ for $K-$ series can be calculated by Stephenson formula (Heitler, 1956):

$$
\eta=\frac{b Z^{4}}{1+b Z^{4}}
$$

where $Z$-atomic number of an element, $b=1,127 * 10^{-6}$;

The obtained expression (2) allows to determine a ratio of mass coefficient of the primary radiation incoherent scattering cross section to mass coefficient of the primary radiation photoelectric absorption using experimentally measured ratios of intensities ofcharacteristic and incoherently scattered radiation of the known energy in a given substance, and hence a required ratio of the number of recoil electrons to the number of photoelectrons.

\subsection{Results obtained with a new method}

The author was the first to obtain a ratio of mass coefficient of the primary radiation incoherent scattering cross section to mass coefficient of photoelectric absorption in heavy metals, molybdenum, and tungsten.

Synthesis and statistical analysis of a number of experimental data (Kosianov, 2005) produces ratio $\frac{J_{2}}{J_{1}}=0,12 \pm 0,03$, respectively ratio $\frac{\sigma_{H}}{\tau_{m}} \approx 0,075 \pm 0,02$ under radionuclide $241 \mathrm{Am}\left(E_{0}=60 \mathrm{keV}\right)$ gamma irradiation of $\mathrm{Mo}(\mathrm{Z}=42)$. Radionuclide $57 \mathrm{Co}\left(E_{0}=120 \mathrm{keV}\right)$ gamma irradiation of $\mathrm{W}(\mathrm{Z}=74)$ gives $\frac{J_{2}}{J_{1}}=0,08 \pm 0,02$, respectively, ratio $\frac{\sigma_{H}}{\tau_{m}} \approx 0,25 \pm 0,02$.

For comparison, Table 2 contains the appropriate ratios, obtained on the basis of theoretical calculations (Losev, 1969).

Table 2. Theoretical ratios of recoil electron sections to photoelectron sections

\begin{tabular}{|l|c|c|c|c|c|}
\hline & $\mathrm{C}(\mathrm{Z}=6)$ & $\mathrm{Al}(\mathrm{Z}=13)$ & $\mathrm{Cu}(\mathrm{Z}=29)$ & $\mathrm{Sn}(\mathrm{Z}=50)$ & $\mathrm{PB}(\mathrm{Z}=82)$ \\
\hline $\mathrm{E}(\mathrm{keV})$ & $\sigma_{{ }_{H}} / \tau_{M}$ & $\sigma_{{ }_{H}} / \tau_{M}$ & $\sigma_{{ }_{u}} / \tau_{M}$ & $\sigma_{{ }} / \tau_{M}$ & $\sigma_{{ }} / \tau_{M}$ \\
\hline 5,12 & 0,003 & 0,00001 & - & - & - \\
\hline 10,24 & 0,096 & 0,0030 & 0,0000096 & - & - \\
\hline 25,60 & 0,184 & 0,092 & 0,000092 & 0,0000092 & - \\
\hline 51,20 & 2,80 & 0,084 & 0,00084 & 0,000084 & 0,0000084 \\
\hline 102,4 & 24,67 & 0,587 & 0,0074 & 0,00074 & 0,000074 \\
\hline 256,0 & 190 & 5,70 & 0,180 & 0,0057 & 0,00057 \\
\hline
\end{tabular}

It follows from the above comparison that the conclusions about substantial discrepancy between theoretical and experimental data are confirmed.

In the modern atomic physics, an electron is taken in a bound state with binding energy $E_{n}$, where quantum number $n$ can vary from 1 to $\infty$ and $\mathrm{E}_{\infty}=0$, i.e. the electron becomes free. Any transition from one bound state to another $E_{2} \rightarrow E_{1}$ can be represented as $E_{2} \rightarrow E_{\infty} \rightarrow E_{1}$, i.e., through a free state. Since the transition time cannot be zero (violation of conservation laws) $\Delta t_{\mathrm{f}}>0$, i.e., for some time, the electron will be in a free state. The contemporary theory of atom is based on quantum mechanics and 
solves the steady-state Schrödinger equation for describing atom. Interaction of electron with light ( $\mathrm{x}$ ray or gamma radiation) is considered as a quantum effect, whereas interaction of electron with a nucleus is considered in terms of continuum theory as the motion of a particle in a continuous and stationary central field (Fig. 2).

(a)

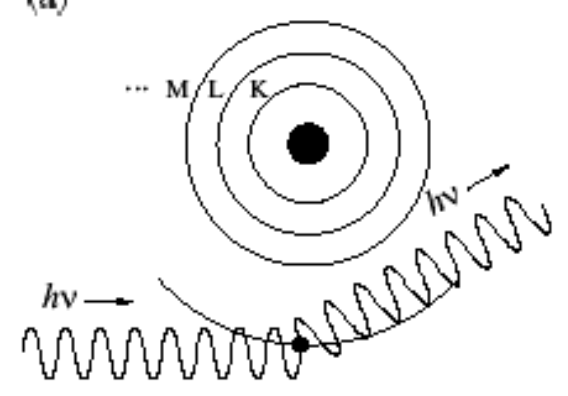

(b)

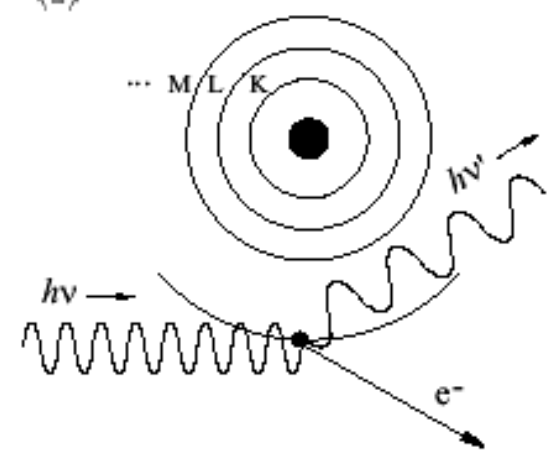

Figure 2. Scattering of photons on atomic electron: a) - coherent scattering; b) - incoherent scattering

But if this interaction is also considered as a result of single collisions of electron (and hence, of the nucleus) with quanta from their total electromagnetic field, the picture will fundamentally change (Fig. $3)$.

a)

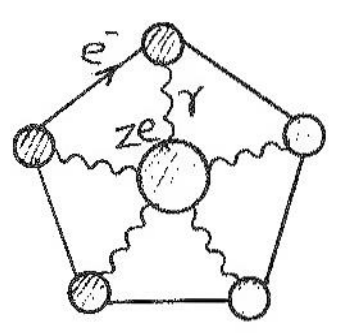

b)

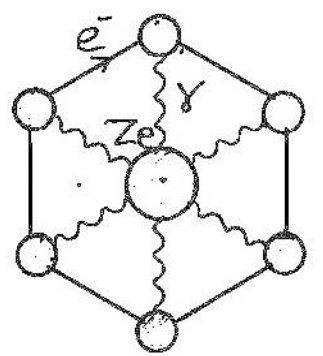

c)

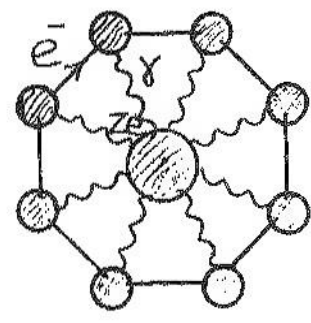

Figure 3. Diagram of electron in $1 \mathrm{~s}$ state of hydrogen-like atom ( $\mathrm{Ze}$ - line of nucleus): a) charge number $-\mathrm{Z}_{1} ; \mathrm{b}$ ) charge number $\left.-\mathrm{Z}_{2}=\mathrm{Z}_{1}+1 ; \mathrm{c}\right)$ charge number $\mathrm{Z}_{3}=\mathrm{Z}_{2}+1$

Electron will be in a free state over some period of timet $t_{\text {free }}$, and in a bound state over $t_{\text {bound }}$ period, with $t_{\text {free }}=N \Delta t_{\text {free }}$, where $\Delta t_{\text {free }}$ is a time period between two successive interactions of electron with the nucleus $t_{\text {bound }}=N \Delta t_{\text {bound }}$, respectively, where $\Delta t_{\text {bound }}$ is a length of one interaction, $N$ is the number of interaction nodes, with $N \sim Z$, since $N \sim F \sim Z$ ( $Z$ is the number of protons in the nucleus).

Let us examine Compton scattering and photo effect using Feynman's diagrams (Fig.4, 5).
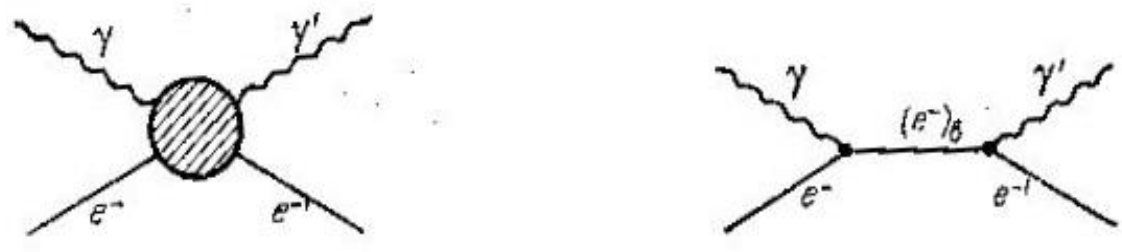
Figure 4. Diagram of Compton scattering of photon on the electron
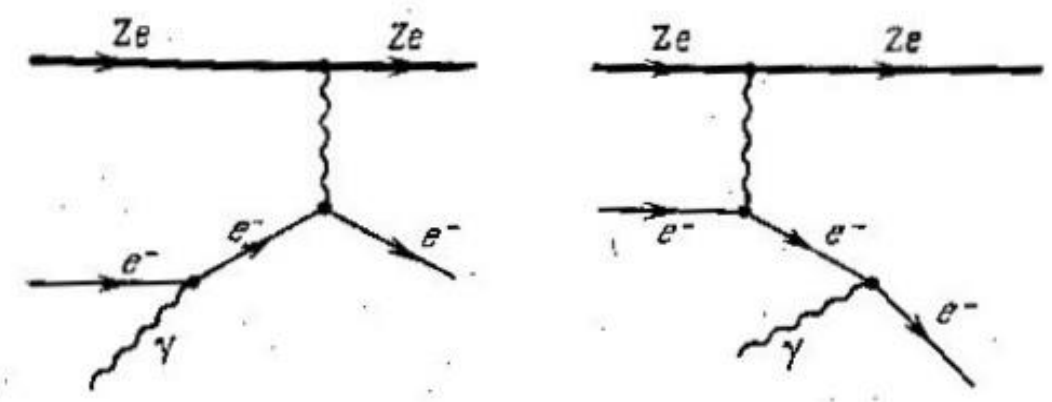

Figure 5. Diagram of photo effect on the atomic electron ( $\mathrm{Ze}-$ the nucleus line )

Compton scattering occurs on a free electron, photo effect involves only bounded electrons.. Therefore, the incoherent scattering section is $\sigma_{H} \sim t_{f} / T$, whereas the photo effect section is $\sigma_{p e} \sim t_{b} / T$, where $T$ is a period of electron revolution. This is a reason why there is such a serious underestimation of incoherent scattering section in theory, where an orbital electron is always taken as bounded, therefore, photo effect section is considerably overestimated. As can be seen in the figure, Compton scattering consists of two points of elementary events when absorption and scattering of photon by electron occur. Duration $\tau_{\text {e.m. }} \sim 10^{-20} \mathrm{c}$ corresponds to the elementary process, hence, $\Delta t_{b}=2 \tau_{\text {e.m. }}$ and $t_{b}=$ $N 2 \tau_{e . m .}$. Accordingly, $t_{f}=T-t_{b}=T-N 2 \tau_{\text {e.m. }}$. But then, at a first approximation, mass photoelectric absorption coefficient $\tau_{m}=\left(t_{b} / T\right) \tau_{m t h}=\left(N 2 \tau_{e . m} / T\right) \tau_{m t h}$, whereas mass coefficient of incoherent scattering section $\sigma_{H}=\left(t_{f} f T\right) \sigma_{H . t h}=\left[\left(T-N 2 \tau_{e . m .}\right) / T\right] \sigma_{H . t h}$, thus, their ratio $\frac{\sigma_{\mathrm{H}}}{\tau_{\mathrm{m}}}=\left(T / N 2 \tau_{e . m .}-1\right)\left(\frac{\sigma_{\mathrm{H}}}{\tau_{\mathrm{m}}}\right)^{*}$, where $\left(\frac{\sigma_{\mathrm{H}}}{\tau_{\mathrm{m}}}\right)^{*}$ is a ratio determined by theory. For example, period $\mathrm{K}$ of hydrogen orbit $T \approx 0,15 * 10^{-15} \mathrm{c}$, hence, ratio $\frac{\sigma_{\mathrm{H}}}{\tau_{\mathrm{m}}} \approx\left(7,5^{*} 10^{3} / N\right)\left(\frac{\sigma_{\mathrm{H}}}{\tau_{\mathrm{m}}}\right)^{*}$.

Thus, there is an explanation provided for a discrepancy between experimentally and theoretically determined ratios of the corresponding values (by one order and more).

\section{CONCLUSIONS}

The author was the first to determine the ratios of the number of recoil electrons to the number of photoelectrons according to experimentally measured ratios of intensities of characteristic and incoherently scattered gamma radiation taking into account matrix effect on molybdenum and tungsten atoms. New results of simultaneously measured ratios of sections for heavy atoms with a method developed by the author, and old measurements of these ratios for light atoms using Wilson cloud chamber, when compared with the results of theoretical calculations, show that there is a significant (by one order and more) one-direction discrepancy for X-ray and gamma emissions over a range of energies in question. Hence, theoretically calculated values of incoherent scattering sections are substantially underestimated, and the values of photo effect sections are, on the contrary, overestimated.

\section{REFERENCIAS}

Briggs, D. (1987). Surface analysis by Auger and X-ray photoelectron spectroscopy. Moscow: Mir.

Heitler, W. (1956). The Quantum Theory of Radiation. Moscow: Izdatelstvo inostrannoy literatury.

Kosianov, P. M. (2005). Calculations of matrix effects in quantitative $X$-ray analysis of the substance having complex chemical composition. Chelyabinsk: YuUrGU. 
Kosianov, P. M. (2012). Compton scattered radiation in X-ray analysis of the substance. Prikladnaya fizika, 4, 15-23.

Kosianov, P. M. (2016). New Method for Determining the Electron Streams in the Metals from the Measured Flows of Scattered Primary Radiation. Materials Science Forum, Switzerland, 870, 735740.

Losev, N. F. (1969). Quantitative X-ray spectrum fluorescence analysis. Moscow: Nauka.

Lukyanova, E. G., \& Podolyako, S. V. (2004). Numerical simulation of X-ray transformation in the objects, taking into account the effect of form factors on the angular distribution of photons. Moscow: Preprint IPM No. 6.

Mamikonyan, S. V. (1976). Apparatus and methods of fluorescent X-ray radiometric analysis. Moscow: Atomizdat.

Morrison, G. H. (1967). Physical methods for trace elemental analysis. Moscow: Mir.

Revenko, A. G. (2000). X-ray fluorescence analysis: state and development trends (review). Zavodskaya laboratoriya, 66(10), 3-19.

Shpolskiy, E. V. (1950). Simultaneity in the Compton effect. The Russian Academy of Sciences, $X \operatorname{LII}(2)$.

Shpolskiy, E. V. (1974). Atomic physics. Vol.1. Moscow: Nauka.

Thompson, M., Baker, M. D., Christie, A., \& Tyson, J. F. (1985). Auger Electron Spectroscopy, Chemical analysis. Series of monographs on analytical chemistry and its applications, 74 . New York: Wiley-Interscience.

\section{SEMBLANCE OF THE AUTHORS}

Petr M. Kosianov: He is a Full Doctor of Physical and Mathematical Sciences, Candidate of Engineering Science, Associate Professor of the Department of Humanitarian-Economic and Natural-Scientific Disciplines of the branch of the Industrial University of Tyumen in Nizhnevartovsk. His fields of scientific interests include spectroscopy, atomic and molecular physics, and optics, radiation, and materials science (miscellaneous). 